\title{
Vaginal Microbial Community Dysbiosis and Associated Outcomes among Women under Contraception at Musasa Health Center, Rwanda
}

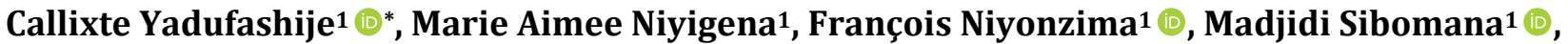 \\ Emmanuel Munyeshyaka1 (ㄷ, Cedrick Izere ${ }^{1}$, Jean Claude Dusabumuremye1, \\ Joseph Mucumbitsi ${ }^{1}{ }^{(0}$, Venant Iyakaremye ${ }^{2}$, John Karemera ${ }^{3}$, Georges Bahati Sangano4, \\ Albert Onyango Mala5, Martin Ndayambaje6, Thierry Habyarimana1 ${ }^{6}$
}

\author{
${ }^{1}$ Department of Biomedical Laboratory Sciences, INES-Ruhengeri Institute of Applied Sciences, Musanze, Rwanda \\ ${ }^{2}$ Musasa Health Center, Rutsiro, Rwanda \\ ${ }^{3}$ Rwanda Forensic Laboratory, Kigali, Rwanda \\ ${ }^{4}$ School of Nursing and Midwifery, University of Rwanda, Kigali, Rwanda \\ ${ }^{5}$ Department of Medical Laboratory Sciences, Jomo Kenyatta University of Agriculture and Technology, Juja, Kenya \\ ${ }^{6}$ Department of Biology, Universite Hassan II de Casablanca, Casablanca, Morrocco \\ Email: ${ }^{\star}$ cyadufashije@ines.ac.rw, ${ }^{\star}$ cyadufashije@gmail.com
}

How to cite this paper: Yadufashije, C., Niyigena, M.A., Niyonzima, F., Sibomana, M., Munyeshyaka, E., Izere, C., Dusabumuremye, J.C., Mucumbitsi, J., Iyakaremye, V., Karemera, J., Sangano, G.B., Mala, A.O., Ndayambaje, M. and Habyarimana, T. (2021) Vaginal Microbial Community Dysbiosis and Associated Outcomes among Women under Contraception at Musasa Health Center, Rwanda. Open Access Library Journal, 8: e7608. https://doi.org/10.4236/oalib.1107608

Received: June 2, 2021

Accepted: July 4, 2021

Published: July 7, 2021

Copyright $\odot 2021$ by author(s) and Open Access Library Inc.

This work is licensed under the Creative Commons Attribution International License (CC BY 4.0).

http://creativecommons.org/licenses/by/4.0/

\begin{abstract}
Background: Vaginal microbiota dysbiosis could lead to the vaginal health conditions. This imbalance in vaginal microbiota can be due to a number of factors including contraceptive methods. Objective: This study was carrried out to investigate the vaginal microbiota dysbiosis and associated vaginal health outcomes among women under contraception at Musasa health Center. Materials and Methods: This was a cross sectional study. 56 vaginal swab samples were collected from women enrolled in a family planning program, and transported to INES Ruhengeri clinical microbiology laboratory for vaginal microbial community analysis. The outcomes were evaluated by scheduled interviews. Chi square test was used to evaluate association of microbiota imbalances in the vagina and the vaginal health outcomes. Results: Lactobacilli (92.85\%) was the most predominant microorganism observed in the vagina. Outcomes of the vaginal microbiota dysbiosis under different contraceptive regimes were observed. Vaginal microbial community imbalance in different family planning methods was statistically significant $\left(x^{2}=\right.$ 36.5, $P=0.049048$ ) to be associated with vaginal health outcomes such as bacterial vaginosis, urinary tract infections, candidiasis and vaginitis. The association with contraceptives contraceptive methods and vaginal microbial
\end{abstract}


community dysbiosis was statistically significant $\left(x^{2}=96.2403, P=0.000491\right)$. The Implant for 5 years and Intrauterine device (IUD) were statistically significant ( $x^{2}=28.533, P=0.002681$ and $x^{2}=27, P=0.004595$ respectively) to contribute to the vaginal microbiota balance. Conclusion: This study established that family planning methods could cause vaginal dysbiosis thereby exposing the vagina to adverse health outcomes and poor reproductive health. Women undergoing family planning should seek medical support if any sign of vaginal infection is observed.

\section{Subject Areas}

Microbiology

\section{Keywords}

Contraception, Dysbiosis, Microbiota, Women, Vagina

\section{Introduction}

Microbiota is a term used in microbiology to describe a collection of microorganism in a particular environment. Each living organism has its own microbiota, and microbiota for human being is known as human microbiota or human microbiome. The human microbiota resides in different locations of the body. There are microorganisms that are located on external part of the body such as the skin, while other microorganisms are located in internal parts of the body like the mucosal epithelia of the intestine, vagina, or the respiratory tract. The microbiota comprises mainly of bacteria, archaea, fungi, protozoa and viruses, and has been associated with a wide range of phenotypes influencing both health and disease [1]. This diversity of microbial organisms, their genetic characteristics and metabolic processes influence the host health and play significant roles, such as the maturation of the immune system, defense against pathogens, access to complex nutrients and degradation of toxic compounds. The complexity of microbial communities and their way of interacting with the host is a clear illustration that both beneficial and pathogenic microbes can be part of the human microbiota, and that in some cases, altering microbial community members can lead to the development of inflammatory processes which have negative consequences for the host [2].

Infection is one of the most common health outcomes caused by imbalances (dysbiosis) of the microbiota. Infectious diesases and their treatment have an impact on the diversity of human microbiota, and this could result to a number of health outcomes in the human host. It should be understood that some drugs like antibiotics and other treatments contribute to dysbiosis of microbiota [3]. Host microbiota interactions are more dynamic; therefore, changes in the microbiota due to antibiotic treatment mostly result to deregulation of host immune homeostasis and an increase of the susceptibility to diseases [4]. Vaginal 
microbiota change is associated with physiological and non-physiological changes mediated by the hormonal status, sexual behavior, contraception practice used, vaginal blood, vaginal showers, presence of foreign bodies and concomitant use of medicines [5]. Family planning is a way to control both birth and child spacing among families across the world, through the use of different contraceptives such as natural planning, or hormonal birth control [6]. These could be a cause of change in vaginal microbiota among women. Vaginal microbiota change is a leading cause of the acquisition of sexually transmitted infections, bacterial vaginosis, vaginitis and urinary tract infections [7].

Vaginal health keeps women in good reproductive health. An imbalance in the vaginal microbiota is risk to vaginal infections which is a barrier to good maternal and child health. The contraceptive methods used by women may alter microbiota present in the vagina. A research conducted by Shoron et al., on the impact of contraceptive initiation on vaginal microbiota revealed that hormonal contraceptive use did not change vaginal microbiota. They also found that contraceptive method such as copper intrauterine device was associated with increased bacterial vaginosis for instance Gardnerella vaginalis and Atopobium vaginae [8]. Commonly used family planning methods are a major cause of alteration of vaginal microbiota, and can lead to a number of vaginal health outcome including gynecological conditions that affect future pregnancy. According to Belizário and Napolitano, bacterial vaginasis reduces the number of lactobacilli in the vaginal tract and increases other members of the microbiota [9]. However, since the introduction of contraceptive methods in Rwanda and other countries in Africa, few studies of the effect of family planning on the imbalances of vaginal microbiota and their health outcomes among women undergoing family planning had been conducted. This study was carried out to highlight the imbalance of the vaginal microbiota associated with the contraceptive utilization and associated viginal outcomes.

\section{Materials and Methods}

\subsection{Methods}

\subsubsection{Study Areas}

This study was carried out at Musasa health center located at Musasa sector, Rustiro district in the Western province of Rwanda. This health center offers services to many people from Musasa sector and other sectors of Rustiro district, Rwanda.

\subsubsection{Study Population and Sample Size}

This study was conducted among 56 women undergoing family planning at Musasa health center, Rutsiro district in Western Province of Rwanda.

\subsubsection{Study Design}

This was a cross sectional study that was carried out from October 2019 to January 2020. Vaginal swabs were collected from women who used various family 
planning methods and the collected samples were analyzed in INES-Ruhengeri clinical microbiology laboratory.

\subsubsection{Sample Processing and Data Collection}

The vaginal swab sample was collected by using cotton bud, which was inserted into the vaginal introitus rotated for about 10 - 30 seconds. It was then withdrawn and put into a test tube. The tube was capped and then mixed with normal saline in order to maintain the morphology of bacteria. The vaginal swab was transported to INES RUHENGERI clinical microbiology laboratory for analysis of vaginal microbiota. Gram staining, culture and biochemical test were performed for microbiological identification. Information and Data regarding vaginal health outcomes were collected using structured interview which was conducted for each woman consented to participate in the study. They were asked the type of family planning they use and some of effects they have faced which were not common before contraceptive methods use.

\subsubsection{Statistical Analysis}

We analyzed both effects of contraceptives on vaginal microbiota balance and vaginal microbiota dysbiosis and associated health outcomes. $x^{2}$ test was used to test association. The considered $\mathrm{P}$ value for statistical significance was $\mathrm{P}<0.05$, the main significance level used in hypothesis testing.

\subsubsection{Ethical Considerations}

The study obtained approval from the Director of Musasa Health Center. This study also applied and was granted ethical clearance form INES-Ruhengeri research directorate. Informed written consent was obtained from the participants. All patients' data gathered in this study were handled confidentially by the researcher. Furthermore, codes were used to identify women from whom the data were obtained.

\subsection{Materials}

Table 1 shows materials used for microbial identification.

\section{Results}

\subsection{Distribution of Age among Study Participants}

Table 2 indicates the demographic characteristics of women under family planning with their frequencies and percentages. The most predominant ages were between $24-26(21.42 \%)$ and $27-29$ (21.42) followed by $30-32$ (17.85\%), 33 37 (14.28\%), $21-23$ (14.28\%) years, Lowest age range was between $18-21$ (10.71\%) years.

\subsection{Contraceptive Methods Used at Musasa Health Center}

The common family planning methods used by women under family planning attending Musasa health center. In the figure, the findings showed that the Im- 
plant for 3 years (32.14\%) is the most common family planning method used by women, followed by the contraceptive Pills (25\%), Injectable (14.28\%), Implant for 5 years $(10.71 \%)$, the lest contraceptive method use was IUD and natural (7.14\%) (Figure 1).

Table 1. Materials used for microbial identification.

\begin{tabular}{|c|c|}
\hline Material Name & Role \\
\hline Sterile cotton stick & It was used to collect vaginal swab samples \\
\hline Normal saline & It was used for irrigation \\
\hline Sterile container & It was used for sample transportation \\
\hline Microscope & To identify Microorganisms in the collected samples \\
\hline $\begin{array}{c}\text { Blood Agar } \\
\text { (HIMEDIA }{ }^{\oplus} \text { Ref M073-500G), }\end{array}$ & $\begin{array}{l}\text { This is enriched media which was used to } \\
\text { isolate fastidious organisms }\end{array}$ \\
\hline $\begin{array}{c}\text { Mannitol Salt Agar } \\
\text { (HIMEDIA }{ }^{\oplus} \text { Ref M118-500G), }\end{array}$ & $\begin{array}{l}\text { This a selective and differential media used to } \\
\text { isolate staphylococcus species }\end{array}$ \\
\hline $\begin{array}{c}\text { MacConkey Agar } \\
\text { (HIMEDIA }{ }^{\circledast} \text { Ref M081-500G) }\end{array}$ & $\begin{array}{l}\text { It was used to isolate gram-negative enteric bacteria. } \\
\text { It helped in differenciating lactose fermenting from } \\
\text { lactose non-fermenting bacteria }\end{array}$ \\
\hline $\begin{array}{l}\text { Sabouraud Dextrose Agar } \\
\text { (TM Media Ref TM 387) }\end{array}$ & $\begin{array}{l}\text { This is non-selective media used to isolate fungi } \\
\text { and yeasts in our studt experiments }\end{array}$ \\
\hline $\begin{array}{c}\text { Kligler's Iron Agar } \\
\text { (HIMEDIA }{ }^{\circledast} \text { Ref M078-500G) }\end{array}$ & $\begin{array}{l}\text { This media was used for the identification of } \\
\text { Enterobacteriaceae, based on double sugar } \\
\text { fermentation and hydrogen sulphide production }\end{array}$ \\
\hline $\begin{array}{c}\text { Simon's Citrate Agar } \\
\text { (HIMEDIA }{ }^{\oplus} \text { Ref M099-500G). }\end{array}$ & $\begin{array}{l}\text { This media was used to differenciate gram-negative } \\
\text { bacteria basing on the citrate utilization }\end{array}$ \\
\hline $\begin{array}{c}\text { Urea Broth } \\
\text { (HIMEDIA }{ }^{\circ} \text { Ref M111-500G) }\end{array}$ & $\begin{array}{l}\text { This is a defferential medium that was used to test } \\
\text { for ability of organisms to produce urease }\end{array}$ \\
\hline $\begin{array}{l}\text { Sulphide Indole Motility } \\
\text { (HIMEDIA }{ }^{\circledast} \text { Ref M181-500G) }\end{array}$ & $\begin{array}{l}\text { This medium was used to differentiate enteric } \\
\text { organisms based on the ability to produce } \\
\text { indole and hydrogen sulfide }\end{array}$ \\
\hline
\end{tabular}

Table 2. Distribution of age among study participants.

\begin{tabular}{ccc}
\hline Age & Frequency & Percent \\
\hline $18-20$ & 6 & $10.71 \%$ \\
$21-23$ & 8 & $14.28 \%$ \\
$24-26$ & 12 & $21.42 \%$ \\
$27-29$ & 12 & $21.42 \%$ \\
$30-32$ & 10 & $17.85 \%$ \\
$33-37$ & 8 & $14.28 \%$ \\
Total & 56 & 100 \\
\hline
\end{tabular}




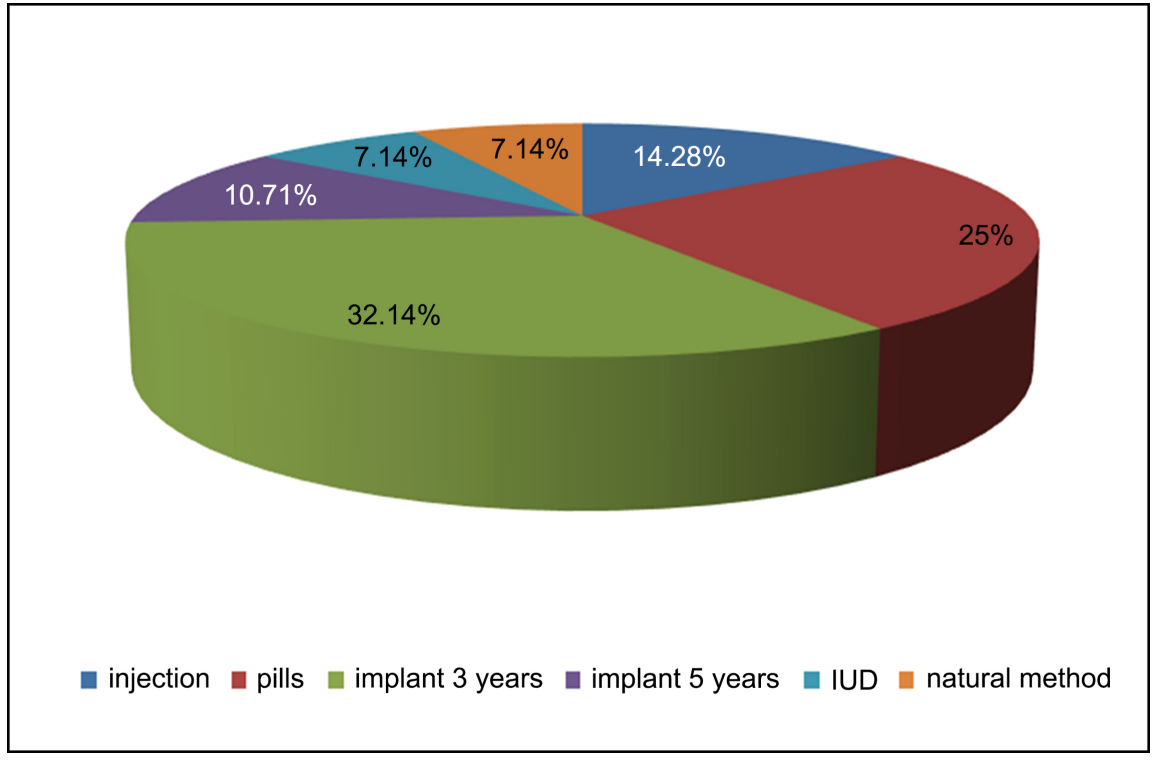

Figure 1. Contraceptive method used.

\subsection{Vaginal Microbiota Composition among Participants}

Figure 2 indicates the various microorganisms isolated from the vagina in 56 women under family planning attending Musasa Health Center. Those microorganisms are E. coli (28.57\%), Klebsiella spp. (3.57\%), Pseudomonas spp. (7.14\%), and Enterobacter ssp (7.14\%), Citrobacter spp. (39.28\%), Serratia Mercescus (3.57\%), Lactobacillus ssp. (92.71\%), Streptococcus spp (14.28\%), Staphylococcus aureus (35.71\%), Staphylococcus Coagulase negative (3.57\%) and Candida albicans (32.14\%). The most isolated bacterium is Lactobacillus which is the most important in vaginal health.

\subsection{Characterization of Vaginal Microbiota in Various Family Planning Methods}

Figure 3 shows the percentages of various microorganisms isolated in different contraceptive methods. In the injectables, Lactobacillus 32\% was the most isolated followed by $S$. aureus $16 \%, C$. albicans $16 \%$, Citrobacter $12 \%$ and Streptococcus $8 \%$. Among the Pill users isolated bacteria were Lactobacillus $37.83 \%$, E. coli $16.21 \%$, S. aureus $10.81 \%$, Streptococcus $5.40 \%$, C. albicans $8.10 \%$, Citrobacter $10.81 \%$, Providencia $5.40 \%$, and Enterobacter $5.40 \%$. For the implant for 3years the most isolated microorganisms were Lactobacillus $32.60 \%$, S. aureus $17.30 \%$, Streptococcus $4.30 \%$, E. coli $13.04 \%$, Enterobacter $13.04 \%$, C. albicans $8.60 \%$, Pseudomonas $6.50 \%$, Serratia $4.30 \%$ and Providencia $4.30 \%$. For the Implant for 5years the most isolated microorganisms were Lactobacillus $37.50 \%$, Streptococcus $12.50 \%$, S. aureus $12.50 \%$, E. coli $13 \%$, Citrobacter $12.50 \%$, Klebsiella $12.50 \%$. IUD isolated microorganisms were Lactobacillus 25\%, C. albicans $25 \%$, Streptococcus $16.60 \%$, and S. coagulase negative $16.60 \%$. Microorganisms that were isolated in clients using the natural method were Lactobacillus 50\% and Citrobacter $50 \%$. 


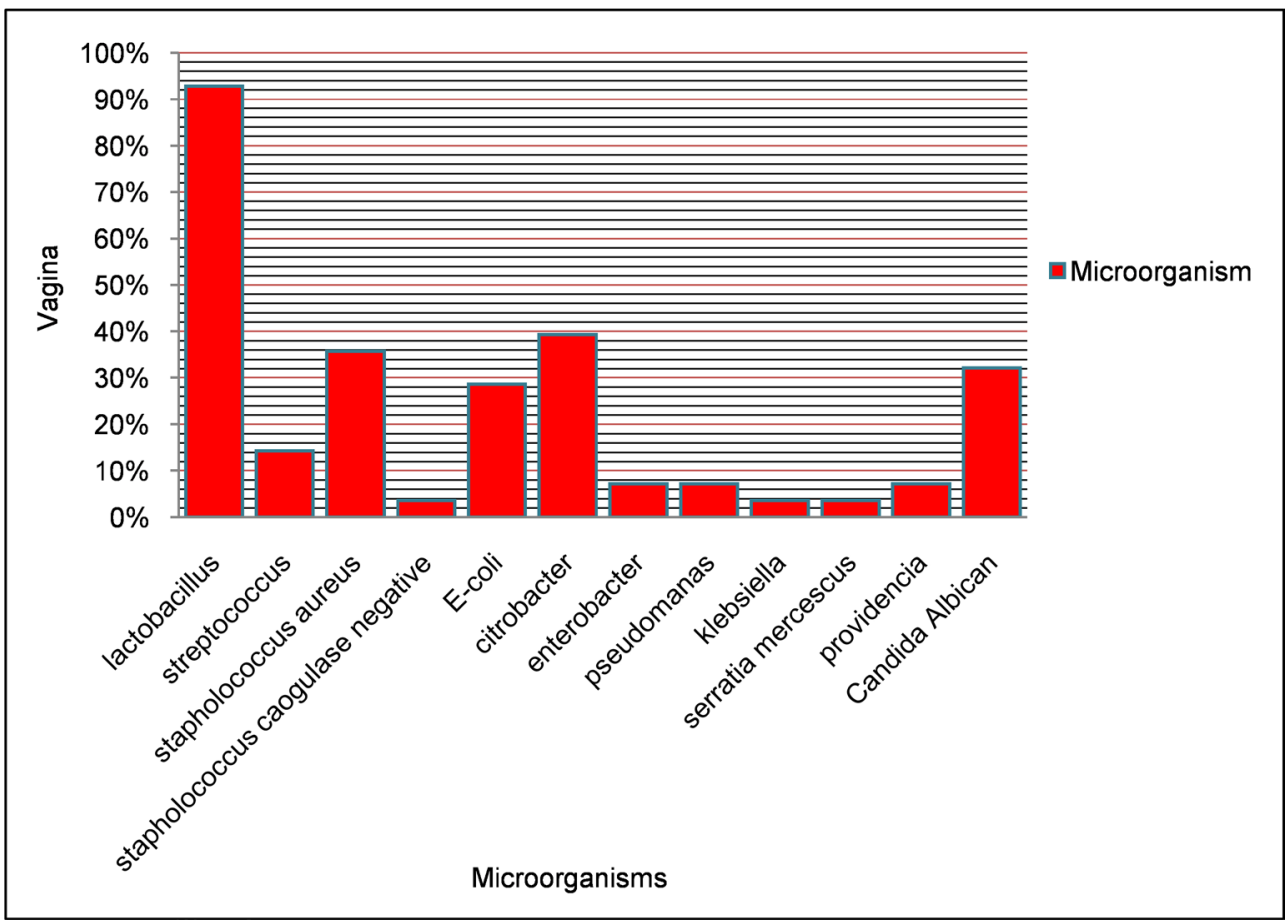

Figure 2. Microorganism isolated in the vagina.

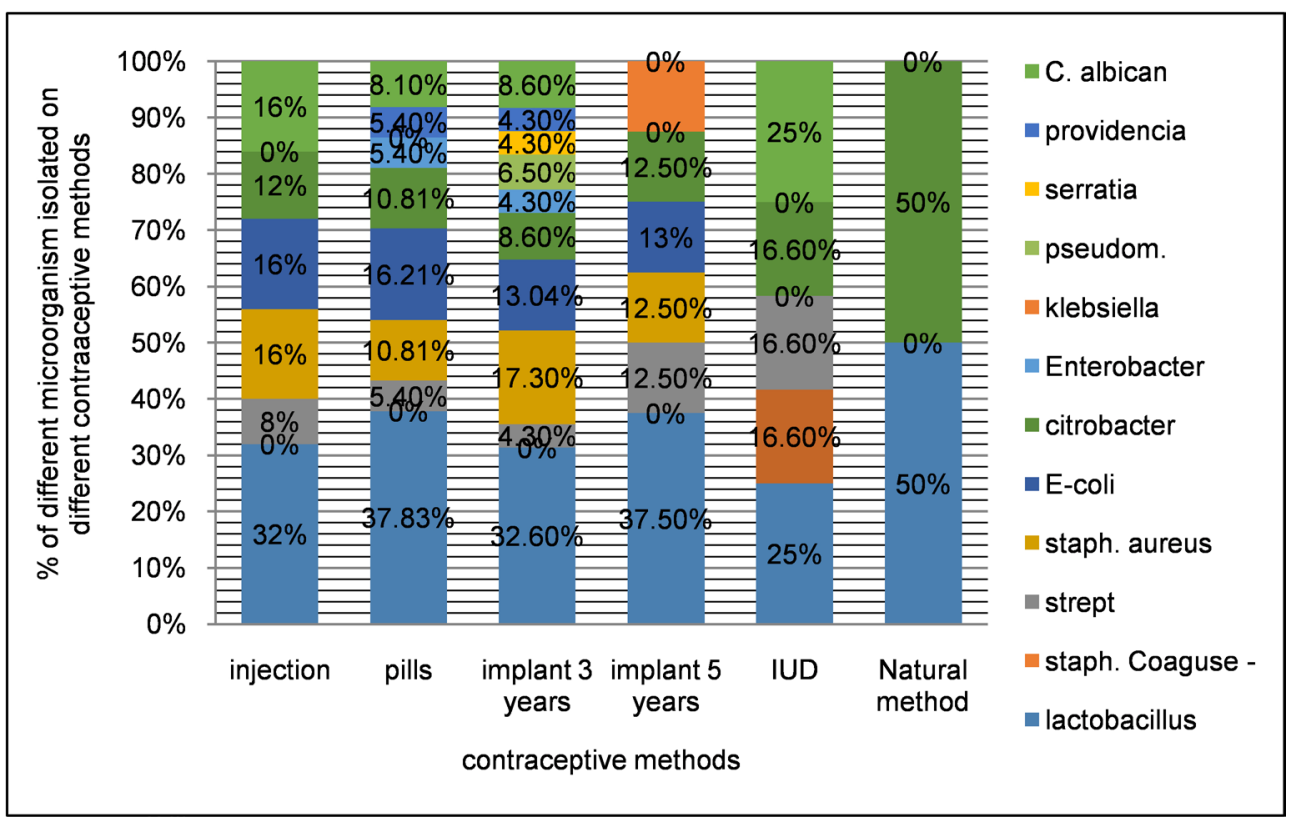

Figure 3. Characterization of vaginal microbiota in various family planning methods.

\subsection{Outcome of Vaginal Microbiota Change}

Figure 4 indicates the rate of vaginal infection found from the sample collected in 56 women under family planning attending Musasa Health Center. Contraceptive methods alter vaginal microbiota and result in vaginal infections. These vaginal infections are candidiasis $14.28 \%$, bacterial vaginosis $17.85 \%$, vaginitis $3.50 \%$, and UTI $10.71 \%$. 


\subsection{Outcomes of Vaginal Microbiota Variation in Various Family Planning Methods at Musasa Health Center}

Figure 5 shows the outcomes of vaginal microbiota variation in different contraceptive methods the results are presented as follows: Injectables: Candidiasis $50 \%$ and bacterial vaginosis $25 \%$. The Pills: Candidiasis $14.28 \%$, BV $14.28 \%$ and UTI $14.28 \%$. The Implant for 3 years: BV25\%, UTI 12.5\% and vaginitis $12.5 \%$. The Implant for 5 years: BV 25\%, IUD: UTI 50\% and natural method with 100\% no effects among users.

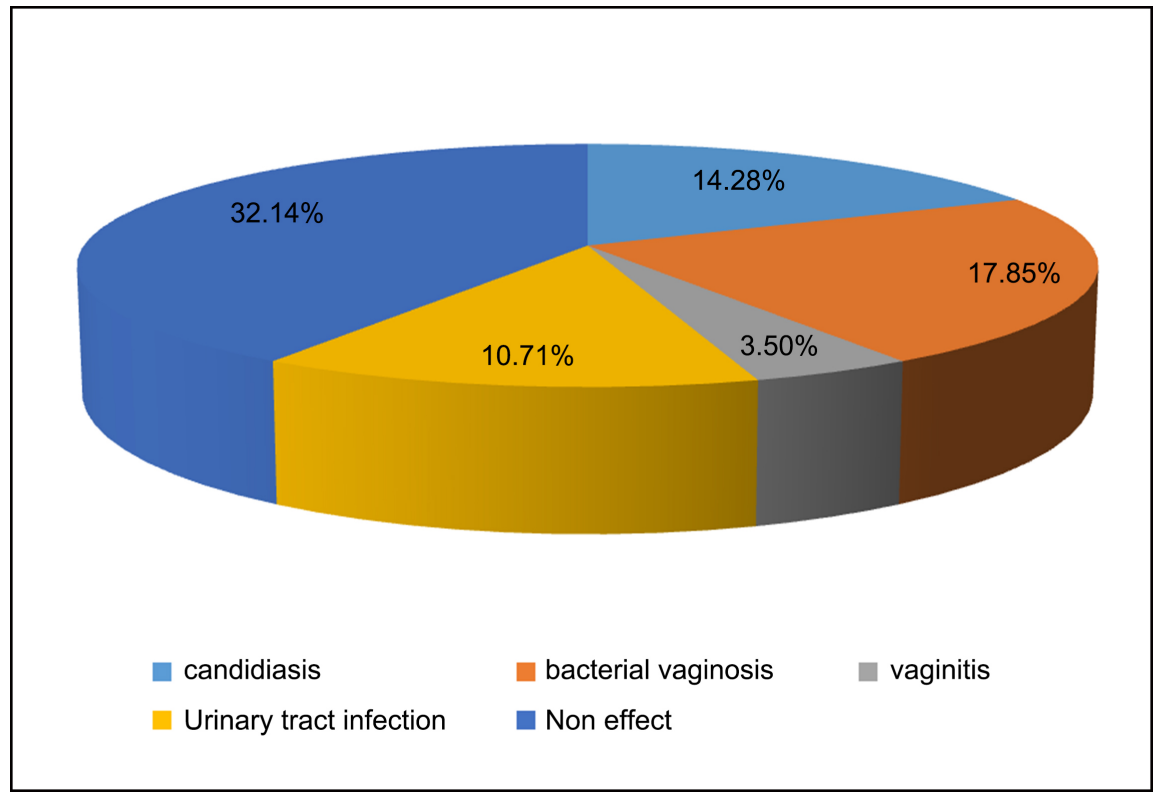

Figure 4. Outcomes of vaginal microbiota variation.

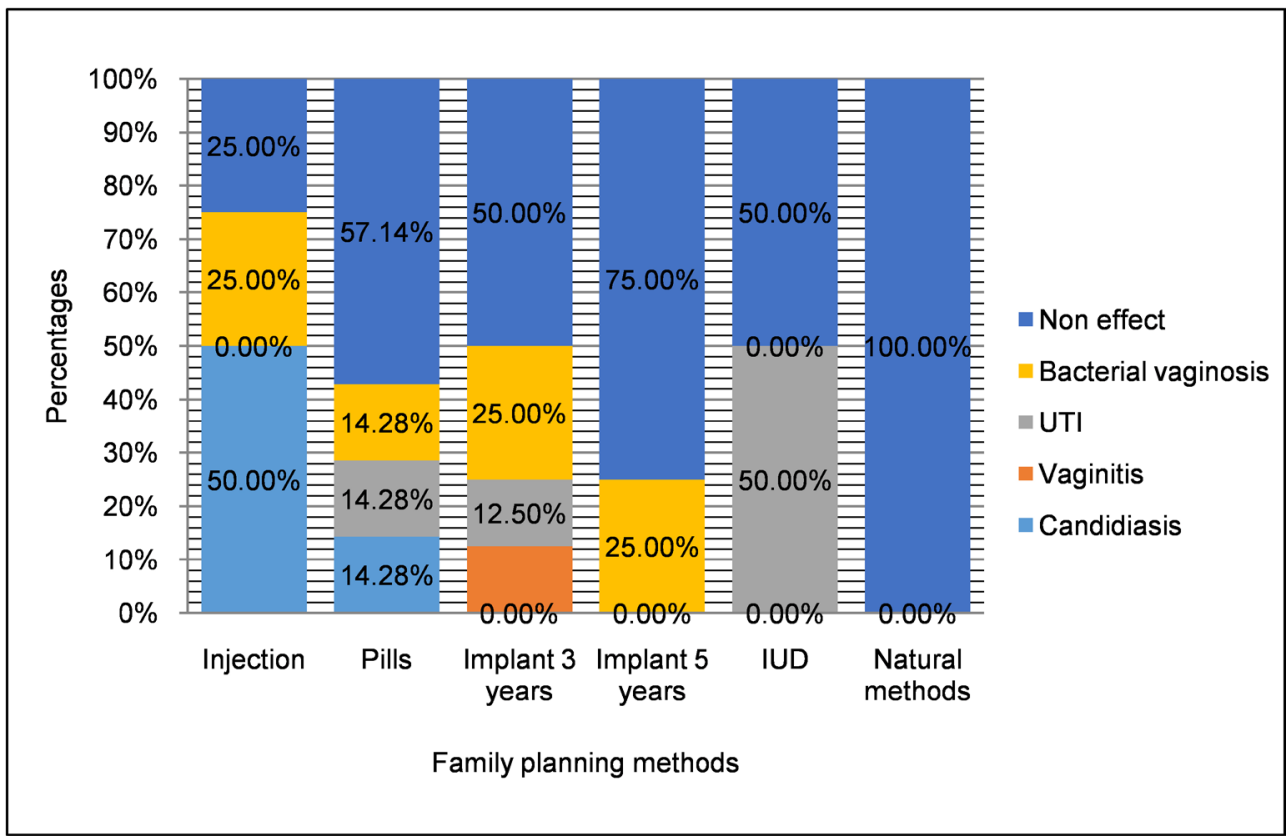

Figure 5. Outcomes of vaginal microbiota variation in various family planning methods. 


\subsection{Association of the Vaginal Microbiota Dysbiosis and Vaginal Health Outcomes}

Table 3 shows association between vaginal microbiota imbalances and vaginal health outcomes. There was statistical significance $\left(x^{2}=36.5, \mathrm{df}=24, \mathrm{P}=\right.$ 0.049048 ) showing the association of vaginal microbiota dysbiosis and vaginal health outcomes. The null hypothesis $\left(\mathrm{H}_{0}\right)$ stated that there is no association between vaginal microbiota variation microbiota and vaginal health outcomes. The Chi square critical value is $x^{2}=36.415$ while calculated value is $x^{2}=36.5$, this implies the rejection of $\mathrm{H}_{\mathrm{o}}$ due to the fact that Chi square critical value is less than calculated Chi square at the level significance $\alpha=0.05$.

\subsection{Association of the Contraceptive Methods and the Vaginal Microbial Community Dysbiosis}

Table 4 shows association between contraceptive methods used at Musasa Health Center and vaginal microbiota isolated. Generally there was statistical significance between contraceptive methods use and the vaginal microbiota imbalance with $\left(x^{2}=96.2403, \mathrm{df}=55, \mathrm{P}=0.000491\right)$. For the single contraceptive method, only the Implant for 5 years and Intrauterine Device were significant $\left(x^{2}\right.$ $=28.533, \mathrm{df}=11, \mathrm{P}=0.002681$ and $x^{2}=27, \mathrm{df}=11, \mathrm{P}=0.004595$ respectively) to affect vaginal microbiota. Other contraceptive methods were not statistically significant. The null hypothesis stated that there was no association between contraceptive methods and vaginal microbiota imbalance. Chi square CV is $x^{2}=$ 73.31 while calculated value is $x^{2}=96.2403$, since the chi square CV is less than calculated value, it implies the rejection of null hypothesis. At this case null hypothesis is rejected.

Table 3. Association of vaginal microbiota with vaginal outcomes.

\begin{tabular}{|c|c|c|c|c|c|c|c|c|}
\hline Health outcomes & Candidiasis & UTI & Vaginitis & BV & Total & Chi Square & $\mathrm{df}$ & P-value \\
\hline \multicolumn{9}{|l|}{ Microbiota Composition } \\
\hline Lactobacillus & $6(6.6)$ & $5(5.6)$ & $2(2)$ & $10(8.6)$ & 23 & & & \\
\hline Staphylococcus aureus & $2(2.3)$ & $2(1.9)$ & $2(0.6)$ & $2(3)$ & 8 & & & \\
\hline Sreptococcus & $2(1.15)$ & $0(0.9)$ & $0(0.34)$ & $2(1.5)$ & 4 & & & \\
\hline S. coagulase negative & $0(0.6)$ & $2(0.5)$ & $0(0.2)$ & $0(0.7)$ & 2 & & & \\
\hline Escherichia coli & $4(2.8)$ & $4(2.4)$ & $0(0.9)$ & $2(3.8)$ & 10 & & & \\
\hline Citobacter & $2(1.15)$ & $0(0.98)$ & $0(0.34)$ & $2(1.5)$ & 4 & & & \\
\hline Enterobacter & $0(1.15)$ & $0(0.98)$ & $0(0.34)$ & $4(1.5)$ & 4 & & & \\
\hline Providencia & $0(1.15)$ & $2(0.98)$ & $0(0.34)$ & $2(1.5)$ & 4 & & & \\
\hline C. albicans & $4(2.8)$ & $2(2.4)$ & $2(0.9)$ & $2(3.8)$ & 10 & & & \\
\hline Total & $20(19.7)$ & $17(16.64)$ & $6(5.96)$ & $26(25.9)$ & $69(68.2)$ & 36.5 & 24 & 0.049048 \\
\hline
\end{tabular}


Table 4. Association of contraceptives and vaginal microbiota variation.

\begin{tabular}{|c|c|c|c|c|c|c|c|c|c|c|c|c|c|c|c|c|}
\hline 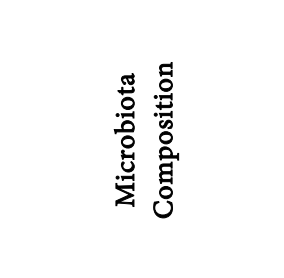 & 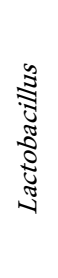 & 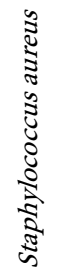 & 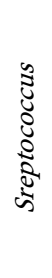 & 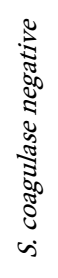 & 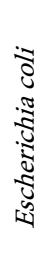 & 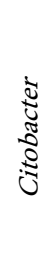 & 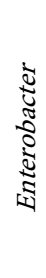 & 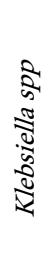 & 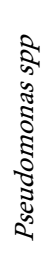 & 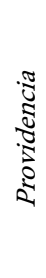 & 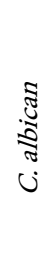 & $\begin{array}{l}\mathbb{\Xi} \\
\mathbb{\Xi} \\
\stackrel{\mathbb{N}}{5}\end{array}$ & సٓ & 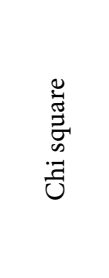 & 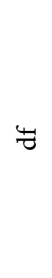 & 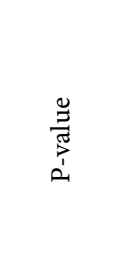 \\
\hline \multicolumn{17}{|l|}{ Contraceptive methods } \\
\hline Intrauterine Device & 3 & 0 & 0 & 2 & 2 & 2 & 0 & 0 & 0 & 0 & 4 & 0 & 13 & 27 & 11 & 0.004595 \\
\hline Injection & 8 & 4 & 2 & 0 & 4 & 4 & 0 & 0 & 0 & 0 & 4 & 0 & 26 & 7.82 & 11 & 0.729332 \\
\hline Implant for 5 years & 6 & 2 & 2 & 0 & 0 & 2 & 2 & 2 & 0 & 0 & 0 & 0 & 16 & 28.533 & 11 & 0.002681 \\
\hline Implant for 3 years & 17 & 8 & 2 & 0 & 6 & 4 & 0 & 0 & 4 & 2 & 4 & 2 & 49 & 13.2123 & 11 & 0.279695 \\
\hline Natural Contraception & 4 & 0 & 0 & 0 & 0 & 4 & 0 & 0 & 0 & 0 & 0 & 0 & 8 & 13.45 & 11 & 0.264933 \\
\hline pills & 14 & 4 & 2 & 0 & 6 & 4 & 2 & 0 & 0 & 2 & 2 & 0 & 36 & 6.225 & 11 & 0.857938 \\
\hline total & 52 & 18 & 8 & 2 & 18 & 18 & 4 & 2 & 4 & 4 & 14 & 2 & 148 & 96.2403 & 55 & 0.000491 \\
\hline
\end{tabular}

\section{Discussion}

This study was carried out to analyze vaginal microbiota imbalances and associated vaginal health conditions among women under contraception. The vaginal microbial community could be favored or unfavored due to the used contraceptive methods. Lactobacillus is the known bacterium that maintains the health of the vagina [10]. Opportuninistic pathogens like E. coli, Klebsialla, Staphylococcus aureus, Streptococcus, Candida albicans and others were isolated from samples collected from women using various contraceptive methods (Figure 3). Previous similar studies have reported Lactobacillus as the predomin at microorgnaism in the vaginal microbial community but with the high growth of pathogenic microorganisms including Gram positive and Gram negative bacteria [11]. In a similar study done on 471 women between 23 - 40 years in Sabhbraj hospital by Achilles et al., found that 369 (78\%) of healthy vaginal microbiota comprised of Lactobacillus spp, followed by E-.Coli 77 (16\%), and Staphylococcus Coagulase negative 6\% [8]. Any discripancies in findings between the current study and other similar previous studies can be attributed to the variations in scope but they revealed the same findings on the vaginal microbial community dysbiosis. Another study carrried out on the assessment of the vaginal microbiota on 345 Brazilian women aged 23 - 40 years by Boris \& Barbés showed that Lactobacillus (79\%) was the most predominant microorganism followed by Enterococci (24\%), Streptococcus, E. coli and others. We observed that an increase of lactobacillus and other bacterial species in the vagina culminated in adverse vaginal health outcomes [12]. 
The present study analyzed the vaginal microbial community differences under different contraceptive regumes. Lactobacillus was the most predominant microorganism in all the contraceptive methods used among women undergoing family planning at Musasa Health Center. However, its frequency increased or decreased depending on the contraceptive method(s) used by study participants. The women who used the Intrauterine devices (IUD) showed the highest reduction of Lactobacillus (25\%) abundance compared to other contraceptive methods. Although, the women who used natural contraceptive methods showed the highest increase in Lactobacillus (50\%). The Implants had the least effect on Lactobacillus (37.5\%) compared to other contraceptive methods. Assuming natural contraceptive users as the control group, we conclude that a decrease in Lactobacillus population favours the proliferation of opportunistic pathogens in the vagina (Figure 3). Use of artificial contraceptive methods could be the leading cause of vaginal microbiota imbalances among women practicing family planning. Similar findings reported the variations in Lactobacillus among users of Pills (50\%), Injectables (65\%), Implant (76\%), and IUD (50\%) [13].

Contraceptive methods use may alter the vaginal microbiota which could lead to the vaginal infections. The current study analyzed vaginal health outcomes presented by women under family planning. Vaginal health outcomes evaluated included Candidiasis, UTI, Vaginitis and Bacterial Vaginosis. There was a high prevalence of UTI (50\%) among women who used the IUD as their method of contraception, but also high prevalence of vaginal Candidiasis (50\%) among women who used Injectables. Bacterial Vaginosis prevalence remained the same in the injectables, and Implant for $3 \& 5$ years. For the natural contraceptive users did not experience negative health outcomes (Figure 4). The vaginal health outcomes increased mostly with the reduction of Lactobacillus on one hand and the presence of other microorganisms on the other. IUD users had low percentages of Lactobacillus, but experienced high levels of Urinary tract infections compared to other methods. The same applied to users of Injectable which were second exhibiting low of levels of Lactobacillus. Candidiasis has found at high level among these users than users of other methods. The similar study was conducted in Dhaka, Bangladesh, isolated Candida species (56.7\%) of the cases compared to (31.1\%) among non-contraceptive users. Among the women using contraceptives, the highest prevalence of $69.4 \%$ was observed among oral pill users compared to those using injections and IUCD who stood at $12.2 \%$ and $2.1 \%$ respectively. The study revealed a strong association between use and the prevalence of vaginal infection by Candida species of which C. albicans was the most common species (72.7\%), Belizário \& Napolitano [9]. In this Indian study the use of oral contraceptive pills (OCP) was the most common cause of vaginitis, followed by injectable and IUCDs in that order. The presence of Estrogen and progesterone hormones in contraceptives increases glycogen in the vagina thereby creating favorable conditions for proliferation or overgrowth of yeast species. The finding of this is study complements our findings that candidiasis is 
higher among women using family planning methods than their counterparts who do not use them.

Bacterial vaginosis is the most common vaginal infection found among women under contraceptives. BV was found in all contraceptive users. Pills (14.28\%), injection (25\%), and the Implant (25\%). This established a trend that showed bacterial vaginosis prevalence to be high (37\%) under the intrauterine device (IUD) compared to women under combined oral contraceptives (19\%) [14]. These findings complement our results on the relationship between the use of contraception and vaginal microbiota variation with the only difference being that $\mathrm{BV}$ prevalence was $0 \%$ in the current study. This can be attributed to a number of underlying confounding health factors in women.

Urinary tract infection stood at $10.71 \%$ among all contraceptive methods but mostly common among users of intra uterine devices $50 \%$. A similar study done by Dienye et al. in Nigeria showed combined prevalence of UTIs among the contraceptive users and controls was $23.7 \%$, with contraceptive users at $35.3 \%$ and controls at $12.0 \%$. The association with UTI prevalence and contraceptive use was statistically significant. [15] We are able to conclude that microbiota variation increases risk to adverse vaginal health outcomes, since the percentage among non-users has been low compared to users.

Vaginitis stood at $3.75 \%$ among users of all contraceptive methods, but was higher among 3 year-implant users $(12.50 \%)$. Vaginitis is the least common vaginal infection among women using different contraceptive methods. According Brotman et al., to oral contraceptives were commonly presented at $10 \%$ and $15 \%$ respectively [16]. Vaginal infections were the common cause of vaginitis. Contraceptives also alter normal physiological function of the body, and then disrupt the composition and abundance of vaginal microbiota such as Lactobacillus. Reduction in abundance of these bacteria are in vaginal microbiota lowers acidity in the vagina and may result in overgrowth of other microorganisms, which then become pathogenic and cause vaginal infections.

Bacterial vaginosis (BV) is due to the alteration of the normal Lactobacillus species toward a more diverse bacterial Flora with overgrowth of facultative and strict anaerobic microorganisms like E. coli, Enterobacter. Miller \& Sobel indicated that BV was significantly associated with Atopobium vaginae, Prevotella spp., and Gardnerella vaginalis [17]. According to Achilles et al., on the study carried out on the 331 University Women of the University of Washington, observed the colonization of $E$. coli in the vagina among users of oral contraceptive Pills, a critical step proceeding urinary tract infection. Candidiasis was due to the imbalance of microorganisms including Lactobacillus spp, S. aureus, streptococcus, Citrobacter and Candida albicans. Roselletti et al., isolated Candida species from $172(49.1 \%)$ out of 350 women. C. albicans was the most frequently isolated species 125 (72.7\%) for candidiasis [12].

Vaginitis was also an outcome of interest that the current study investigated. Common bacteria isolated in vaginitis were $S$. aureus, Citrobacter, L. actobacillus 
and Candida albicans, but contrast according to Enweani et al on the study done on evaluation of the effect of contraceptives on prevalence of Candida Species on in Dhaka, Bangladesh on 631 patients attending routine prenatal care from a vaginitis clinic by vaginitis is caused by a displacement of the healthy vaginal Lactobacillus species with aerobic pathogens such as Escherichia coli, Group B Streptococcus (GBS), Staphylococcus aureus, and Enterococci faecalis [18].

The association between contraceptive methods used by women and the vaginal microbial community alteration was investigated by the current study. Generally Contraceptive methods were significant to be the leading cause of vaginal microbial community dysbiosis. Each contraceptive method was studied to investigate its potential to affect vaginal microbiota, but only the Implant for 5 years and IUD were significant to affect all the vaginal microbiota composition (Table 4). The contraction was shown to the findings on the effects of intrauterine contraception on the vaginal microbiota where there was no statistical significance showing the effect of intrauterine contraception on vaginal microbiota [19]. Various studies reported that vaginal microbiota could change depending on how long the woman has been using the contraceptive method. The study conducted Gupta et al. showed the difference of vaginal microbiota depending on the type of contraceptive methods, however not all contraceptive methods were significant to affect vaginal microbiota. Some of the same microbiota composition of the current study was isolated but the clear difference is that this compared study had a baseline vaginal microbiota [20].

\section{Conclusion}

Contraceptive methods could lead to the vaginal microbial community dysbiosis, a leading cause of a number of adverse health outcomes among women under family planning. Reduction of Lactobacillus was the cause for proliferation of opportunistic microorganisms exposing to the vaginal infections such as bacterial vaginosis, Vaginal Candidiasis, Urinary Tract Infections and Vaginitis. There was a high prevalence of UTI and Vaginal candidiasis among women who used IUD and Injectable respectively. However, only BV was significantly associated with vaginal microbial community dysbiosis.

\section{Acknowledgements}

Our great thanks are addressed to Musasa health Center staff for accepting and supporting us for data and sample collection. Our thanks also go to clinical microbiology laboratory staff at INES-Ruhengeri-Institute of Applied Sciences for laboratory results analysis.

\section{Author Contribution}

CY: brought the idea of the work, drafted the manuscript and analyzed data, MAN: Data collection and records and summary, FN: review of the manuscript, SM: assisted in data analysis, EM: assisted laboratory techniques, CI: manuscript 
review, JCD: manuscript review, JM: Laboratory techniques design, VI: assisted data collection, JK: Laboratory techniques methodology design, GBS: manuscript review, AOM: language editing and discussion improvement, $\mathrm{MN}$ : manuscript review, TH: reviewed the manuscript and methodology design.

\section{Data Availability}

All about dataset are available via corresponding author.

\section{Ethical Approval and Consent for Participation}

Research committee of INES Ruhengeri Institute of applied sciences provided an ethical letter for this study to be carried out, but also Musasa Health Center provided an ethical approval for sample collection in family planning service. All women were explained about the study before sample collection, and those who voluntarily accepted were recruited.

\section{Conflicts of Interest}

The authors declare no conflicts of interest.

\section{References}

[1] Botero, L.E., Delgado-Serrano, L., Cepeda Hernandez, M.L., Del Portillo Obando, P. and Zambrano Eder, M.M. (2016) Human Microbiota: The Role of Microbial Communities in Health Disease. Acta Biologica Colombiona, 21, 5-15. https://doi.org/10.15446/abc.v21n1.49761

[2] Flint, H.J., Scott, K.P., Louis, P. and Duncan, S.H. (2012) Role of Gut Microbiota in Nutrition and Health. Nature Review Gastroenterology \& Hematology, 9, 577-580. https://doi.org/10.1038/nrgastro.2012.156

[3] Levy, M., Kolodziejczyk, A.A., Thaiss, C.A. and Elinav, E. (2017) Dysbiosis and Immune System. Nature Reviews Immunology, 17, 219-221. https://doi.org/10.1038/nri.2017.7

[4] Willing, B.P., Russell, S.L. and Finlay, B.B. (2011) Shifting the Balance: Antibiotic Effect on host-Microbiota Mutualism. Nature Reviews Microbiology, 9, 233-236. https://doi.org/10.1038/nrmicro2536

[5] Geeraerts, W., De Vuyst, L. and Leroy, F. (2019) Mapping the Dominant Microbial Species Diversity at Expiration Date of Raw Meat and Processed Meats from Equine Origin, an Underexplored Meat Ecosystem, in the Belgian Retail. International Journal of Food Microbiology, 29, 189-199. https://doi.org/10.1016/j.ijfoodmicro.2018.09.019

[6] Yeakey, M.P., Muntifering, C.J., Ramachandran, D.V., Myint, Y., Creanga, A.A., Tsui, A.O. (2009) How Contraceptive Use Affect Birth Interval: Result of Literature Review. Studies in Family Planning, 40, 205-214. https://doi.org/10.1111/j.1728-4465.2009.00203.x

[7] Paavonen, J. and Brunham, R.C. (2018) Bacterial Vaginosis and Desquamative Inflammatory Vaginitis. New England Journal of Medicine, 379, 2246-2254. https://doi.org/10.1056/NEJMra1808418

[8] Achilles, S.L., Austin, M.N., Meyn, L.A., Mhlanga, F., Chirenje, Z.M. and Hillier, S.L. (2018) Impact of Contraceptive Initiation on Vaginal Microbiota. American 
Journal of Obstetrics \& Gynecology, 218, 622.e1-622.e10. https://doi.org/10.1016/j.ajog.2018.02.017

[9] Belizário, J.E. and Napolitano, M. (2015) Human Microbiome and Their Role in Dysbiosis, Common Disease and Novel Therapetic Approaches. Frontiers in Microbiology, 5, 1050-1054. https://doi.org/10.3389/fmicb.2015.01050

[10] Mikelsaar, M. and Zilmer, M. (2009) Lactobacillus fermentum ME-3-An Antimicrobial and Antioxidative Probiotic. Microbial Ecology in Health \& Disease, 21, 1-27. https://doi.org/10.1080/08910600902815561

[11] Amabebe, E. and Anumba, D.O.C. (2012) The Vaginal Microenvironment: The Physiologic Role of Lactobacilli. Frontiers in Medicine, 5, Article No. 181. https://doi.org/10.3389/fmed.2018.00181

[12] Boris, S. and Barbés, C. (2000) Role Played by Lactobacillus in Controlling the Population of Vaginal Pathogens. Microbes and Infection, 2, 543-546. https://doi.org/10.1016/S1286-4579(00)00313-0

[13] Fosch, S.E., Yones, C., Trossero, M. and Grosso, O. (2013) Influence of Different Contraceptive Method on Vaginal Microbiota: Clinical Study. Health, 5, 19-24. https://doi.org/10.4236/health.2013.57A4003

[14] Madden, T., Grentzer, J.M., Secura, G.M., Allsworth, J.E. and Peipert, J.F. (2012) Risk of Bacterial Vaginosis in Users of the Intrauterine Device: A Longitudinal Study. Sexually Transmitted Diseases, 39, 217-222. https://doi.org/10.1097/OLQ.0b013e31823e68fe

[15] Dienye, P.O., Gbeneol, P.K. and Dienye, P. (2011) Contraception as a Risk Factor for Urinary Tract Infection in Port Harcourt. Nigeria: A Case Control Study. African Journal of Primary Health Care \& Family Medicine, 3, Article No. a207. https://doi.org/10.4102/phcfm.v3i1.207

[16] Brotman, R.M., Bradford, L.L., Conrad, M., Gajer, P., Ault, K., Peralta, L., Ravel, J., et al. (2012) Association between Trichomonas vaginalis and Vaginal Bacterial Community Composition among Reproductive Age Women. Sexually Transmitted Diseases, 39, 807-812. https://doi.org/10.1097/OLQ.0b013e3182631c79

[17] Miller, K.W. and Sobel, J.D. (2010) Dynamics of the Vaginal Ecosystem: Hormonal Influences. Infectious Diseases: Research and Treatment, 23, 10-14. https://doi.org/10.4137/IDRT.S3903

[18] Enweani, I.B., Gugnani, H.C., Okobia, R.A. and Ojo, S.B. (2001) Effect of Contraceptives Method on Prevalence of Vaginal Colonization with Candida Species in Edo state, Nigeria. Revista Iberoamericana de Micologia, 18, 171-173.

[19] Bassis, C.M., Jenifer, E.A, Heather, N.W., Daniel, E.S., Vincent, B.Y. and Jason, D.B. (2017) Effects of Intrauterine Contraception on the Vaginal Microbiota. Contraception, 96, 189-195. https://doi.org/10.1016/j.contraception.2017.05.017

[20] Gupta, K., Roberts, P.L., Hillier, L.S., Hooton, M.T. and Stamm, E.W. (2000) Effects of Contraceptive Method on the Vaginal Microbial Flora: A Prospective Evaluation. The Journal of Infectious Diseases, 181, 595-601. https://doi.org/10.1086/315267 